\title{
Enhancing the stability of copper chromite catalysts for the selective hydrogenation of furfural using ALD overcoating
}

Hongbo Zhang ${ }^{\mathrm{a}}$, Yu Lei ${ }^{\mathrm{b}, \mathrm{c}}$, A. Jeremy Kropf ${ }^{\mathrm{a}}$, Guanghui Zhang ${ }^{\mathrm{a}}$, Jeffery W. Elam ${ }^{\mathrm{b}, *}$, Jeffery T. Miller ${ }^{\mathrm{a}}$, Fred Sollberger ${ }^{\mathrm{d}}$, Fabio Ribeiro ${ }^{\mathrm{d}}$, Cem M. Akatay ${ }^{\mathrm{e}}$, Eric A. Stach ${ }^{\mathrm{f}}$, James A. Dumesic $^{\mathrm{g}}$ and Christopher L. Marshall ${ }^{\mathrm{a}, *}$

a Chemical Science and Engineering Division, Argonne National Laboratory, Argonne, IL 60439, USA

b Energy Systems Division, Argonne National Laboratory, Argonne, IL 60439, USA

c Current address: Department of Chemical and Materials Engineering, University of Alabama in Huntsville, Huntsville, AL 35899, USA

d FRNY 2158 Purdue University School of Chemical Engineering Forney Hall of Chemical Engineering 480 Stadium Mall Drive West Lafayette, IN 47907-2100

e Nanotechnology Center Purdue University 1205 West Lafayette, IN, 47907, USA

f Center for Functional Nanomaterials Brookhaven National Laboratory Upton, NY, 11973, USA

g Department of Chemical and Biological Engineering, University of Wisconsin, Madison, WI 53706, USA

*Authors to whom correspondence should be addressed: marshall@anl.gov

To be submitted to Journal of Catalysis 


\begin{abstract}
The stability of a gas phase furfural hydrogenation catalyst $\left(\mathrm{CuCr}_{2} \mathrm{O}_{4} \cdot \mathrm{CuO}\right)$ was enhanced by depositing a thin $\mathrm{Al}_{2} \mathrm{O}_{3}$ layer using atomic layer deposition (ALD). Based on temperatureprogramed reduction (TPR) measurements, the reduction temperature of $\mathrm{Cu}$ was raised significantly, and the activation energy for furfural reduction was decreased following the ALD treatment. Thinner ALD layers yielded higher furfural hydrogenation activities. X-ray absorption fine structure (XAFS) spectroscopy studies indicated that $\mathrm{Cu}^{1+} / \mathrm{Cu}^{0}$ are the active species for furfural reduction.
\end{abstract}

Key Words: Selective hydrogenation, 2-Furfuraldehyde, Furfuryl alcohol, Stability, Copper chromite, TPR, XAFS, ALD, operando 


\section{Introduction}

Fossil fuels provide the majority of our current energy supply, especially in the transportation fuel sector. ${ }^{1}$ These fossil fuel resources took millions of years to be formed, and are currently being consumed at a rate that is orders of magnitude higher than their natural regeneration cycle, making them non-renewable sources of energy. Fuels generated from biologically-derived feedstocks are a good alternative to replace fossil sources. ${ }^{2}$ Furfuryl alcohol, an important intermediate molecule in the conversion of biomass to the biofuels, can be synthesized via the selective hydrogenation of furfural, an important step along the route for converting hemi-cellulosic materials into biofuels. ${ }^{3}$

Copper chromite $\left(\mathrm{CuCr}_{2} \mathrm{O}_{4} \cdot \mathrm{CuO}\right)$, due to its mild catalytic reduction properties, has been used extensively for years in various industrial processes such as the partial hydrogenation of vegetable oils and fatty acids as well as the decomposition or dehydration of alcohols. ${ }^{4}$ The utilization of these catalysts in hydrogenation reactions stems from their capability to selectively hydrogenate carbonyl bonds while leaving unsaturated $\mathrm{C}=\mathrm{C}$ bonds virtually untouched. This same catalyst has also been used for the reduction of furfural due to its high activity and selectivity to furfuryl alcohol. ${ }^{5}$ However, copper chromite catalysts suffer severe deactivation under the normal working conditions. For instance, the total activity for furfural reduction can decrease by $40 \%$ in $4 \mathrm{~h}$ at a $52 \mathrm{~h}^{-1}$ WHSV for a commercial copper chromite catalyst. ${ }^{6}$ Previous work has shown that coke formation, metal sintering/leaching ${ }^{7}$, and support migration over the

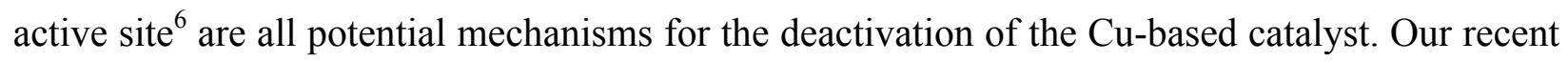
results have shown that coke formation along with chromite migration over the active sites of $\mathrm{Cu}$ are the major causes for deactivation of the $\mathrm{Cu}$-chromite catalyst in the gas phase reduction of furfural. ${ }^{6}$ 
Recently, $\mathrm{Lu}^{8}$ and co-workers discovered that coke formation and sintering can be prevented in the oxidative dehydrogenation of ethane by applying $\mathrm{Al}_{2} \mathrm{O}_{3}$ ALD "overcoatings" to palladium nanoparticles, significantly improving the yield of ethylene. Though initially fully covered by $\mathrm{Al}_{2} \mathrm{O}_{3}$ thin films, the $\mathrm{Al}_{2} \mathrm{O}_{3}$-coated Pd NPs became accessible to reagent gases through annealing the catalyst to induce microporosity in the overcoating layer following. In addition, they speculated that the $\mathrm{Al}_{2} \mathrm{O}_{3}$ overcoat preferentially segregated onto step edges and surface defects that, if exposed, are believed to break C-C bonds leading to coke formation. ${ }^{9}$ ALD-modification of heterogeneous catalysts has proved beneficial in other applications, such as carbon nanotube growth ${ }^{10}$, $\mathrm{CO}$ oxidation ${ }^{11}$, lithium- $\mathrm{O}_{2}$ batteries, ${ }^{12}$ and biomass conversion. ${ }^{13}$ Recently, Dumesic ${ }^{7}$ and coworkers found that $\mathrm{ALD} \mathrm{Al}_{2} \mathrm{O}_{3}$ overcoating can suppress the deactivation of $\mathrm{Cu}$ caused by sintering and leaching of the metal under trickle bed conditions. These workers found that the deactivation of the ALD catalyst by the deposition of carbonaceous species (i.e., coke) is reversible upon calcination, whereas deactivation of the same catalyst without the ALD overcoating by $\mathrm{Cu}$ leaching or sintering is irreversible. However, this previous work did not examine the effects of catalyst overcoating for vapor phase furfural hydrogenation, which is thought to be a much more promising process for furfural conversion. In addition, the mechanism by which the ALD layers modify the metal nanoparticles underneath is still unclear.

In the current work, in situ and operando X-ray absorption methods were used to elucidate the mechanism of alumina ALD overcoating of $\mathrm{Cu}$ nanoparticles and the effect of ALD overcoatings against vapor phase furfural reduction reactions over $\mathrm{Cu}$-chromite. A factor analysis method was used to break down the XANES spectra into several components corresponding to different $\mathrm{Cu}$ states, and these were analyzed during the reductions. Different numbers of $\mathrm{ALD} \mathrm{Al}_{2} \mathrm{O}_{3}$ cycles were performed on the $\mathrm{Cu}$ catalysts to vary the thickness of the 
protective overcoats and evaluate the effect of thickness on the $\mathrm{Cu}$ reduction and the furfural hydrogenation reaction. This report will provide insight into the reduction process of $\mathrm{Cu}-$ chromite before and after ALD treatment, and demonstrate that the ALD process can improve the stability of $\mathrm{Cu}$-chromite catalysts in vapor phase furfural hydrogenation. Finally, we will show that $\mathrm{Cu}^{1+} / \mathrm{Cu}^{0}$ are the active species for this reaction. 


\section{Materials and Methods}

\section{Materials}

The commercial copper chromite catalyst (Cu-chromite), and 2-Furfuraldehyde (Reagent, $>99 \%$ ) were both purchased from Sigma-Aldrich. Hydrogen and nitrogen gases were all UHP level, obtained from Airgas*.

\section{Atomic Layer Deposition}

ALD was performed in a viscous flow reactor that has been described in detail elsewhere. ${ }^{14} 0.5 \mathrm{~g} \mathrm{Cu}$-chromite powder was spread uniformly onto a stainless steel sample plate with a mesh top to contain the powder while still allowing gaseous access to the precursor vapors

15. The samples were loaded into the reactor and kept for at least 30 minutes at $200{ }^{\circ} \mathrm{C}$ in a 160 sccm flow of UHP $\mathrm{N}_{2}$ at 1 Torr pressure to allow temperature stabilization and to dry the powder. Next, the $\mathrm{Cu}$-chromite catalyst was coated with $10,20,30$ and $45 \mathrm{ALD}$ cycles of $\mathrm{Al}_{2} \mathrm{O}_{3}$. These samples are denoted as, e.g., ALD Cu-chromite-10c for the $10 \mathrm{ALD} \mathrm{Al}_{2} \mathrm{O}_{3}$ cycle -treated $\mathrm{Cu}$-chromite. The $\mathrm{Al}_{2} \mathrm{O}_{3}$ ALD used alternating exposures to trimethyl aluminum (TMA, SigmaAldrich, 97\%) and deionized water at $200{ }^{\circ} \mathrm{C}$. Typical timing sequences for a single $\mathrm{Al}_{2} \mathrm{O}_{3} \mathrm{ALD}$ cycle are: TMA dose (60s) - purge (120s) - $\mathrm{H}_{2} \mathrm{O}$ dose (60s) - purge (120s).

Post-treatment in flowing $\mathrm{N}_{2}$ at $700{ }^{\circ} \mathrm{C}$ was performed to induce porosity in the ALD Cuchromite catalysts. These post-treated samples are labeled as, e.g., ALD Cu-chromite-10c-700 for $10 \mathrm{ALD}$ alumina cycles over $\mathrm{Cu}$-chromite followed by heat-treatment at $700^{\circ} \mathrm{C}$.

\section{Vapor Phase Hydrogenation of 2-Furfuraldehyde}


Vapor phase conversion of 2-furfuraldehyde (furfural) over ALD-treated copper chromite was conducted at atmospheric pressure in a $1 / 2$ " stainless steel tubular reactor placed in a clamshell furnace equipped with temperature controllers. For each reaction test, about $60-65 \mathrm{mg}$ of ALD-treated Cu-chromite (or 30mg Cu-chromite) was diluted with $\mathrm{SiC}$ (70 mesh, mass ratio of sample to diluent is 1:12) to mitigate hot spot formation in the catalyst bed due to the exothermic nature of this reaction. The sample was then loaded onto a quartz wool bed, sitting on a $1 / 4$ " stainless steel tubing located at the bottom half of the reactor to help fix the bed position.

Prior to reaction, the catalyst was reduced in situ in $10 \% \mathrm{H}_{2} / \mathrm{He}$ for 1 hour at $200^{\circ} \mathrm{C}$. After reduction, $50 \% \mathrm{H}_{2} / \mathrm{He}$ was purged into the unit for half an hour to allow stabilization. Furfural was introduced to the reactor by sweeping a carrier gas of $50 \% \mathrm{H}_{2} / \mathrm{He}$ through a bubbler containing pure furfural. The bubbler temperature was controlled by a circulating bath. Reactor effluents were analyzed by an online gas chromatography equipped with a flame ionization detector (FID) and a packed column (EC-Wax, 30m * 0.32mm*1 $1 \mu \mathrm{m}$, ECONO-CAP, Grace Davison). All the chemical transfer lines and valves, from the bubbler to the online GC injector, as well as the gas sampling valve in the GC were heat traced to prevent condensation of either the reactant or the products. Cold spot avoidance is key to obtaining high quality, stable and accurate data with proper mass balances.

Selective hydrogenation of furfural was studied over $\mathrm{Cu}$-chromite, ALD Cu-chromite10c-700, ALD Cu-chromite-20c-700, ALD Cu-chromite-30c-700 and ALD Cu-chromite-45c700 , respectively. Typical reaction conditions were $2 \%$ furfural and $50 \%$ of $\mathrm{H}_{2}$ to make the ratio of $\mathrm{H}_{2}$ : furfural $=25: 1$ and a total gas flow rate between $50-100 \mathrm{cc} / \mathrm{min}$. WHSV was defined as the total mass flow rate of furfural divided by the total mass of the copper-chromite catalyst. Fresh catalyst was used each time to ensure identical reaction conditions. 


\section{X-ray absorption fine structure (XAFS) data collection and analysis}

In situ X-ray absorption measurements at $\mathrm{Cu} \mathrm{K}$-edge $(8,980.48 \mathrm{eV})$ were conducted at the Materials Research Collaborative Access Team (MRCAT) 10ID (insertion device) and 10BM (bending magnet) at the Advanced Photon Source (APS) at Argonne National Laboratory. $\mathrm{Cu}-\mathrm{K}$ edge XAS spectra were collected in transmission mode with minimum data point interval of 0.5 $\mathrm{eV}$. Each spectrum took about 1.5 minutes of scanning. $\mathrm{A} \mathrm{Cu}$ foil spectrum was acquired simultaneously with each measurement for energy calibration. Approximately $10 \mathrm{mg}$ of up to three samples were loaded as self-supporting wafers into a multi-sample stainless steel holder with six individual 0.12 in. diameter holes. The holder was placed into a quartz sample tube ( 1 in. o.d.), centered in a clam-shell furnace, described by Neylon et al. ${ }^{16}$ The sample temperature was measured by a thermocouple positioned near the sample holder inside the quartz tube. Before starting the TPR process, all the samples were first heated to $150{ }^{\circ} \mathrm{C}$ for 30 min to eliminate moisture and other adsorbed molecules from the catalyst surface. Then the samples in the cell were heated up to $700{ }^{\circ} \mathrm{C}$ with a ramp rate of $2{ }^{\circ} \mathrm{C} / \mathrm{min}$ under a $60 \mathrm{sccm}$ flow of $\mathrm{H}_{2}(3.5 \%)$ in He. Scans of all samples were recorded every 1-2min during the TPR process with 70-80 spectra per sample collected during each run. Every second spectrum is plotted here.

\section{Temperature programmed reduction (TPR)}

TPR was performed on an Altamira AM-200 unit equipped with a thermal conductivity detector (TCD). The outlet gases were also analyzed by a Stanford Research System Residual Gas Analyzer (RGA, mass spectrometer). Approximately, 80-100 mg of sample were loaded into a $1 / 8$ in. quartz U-tube and installed on the unit. Prior to the TPR runs, each sample was pretreated in $50 \mathrm{sccm} \mathrm{He}$ at $150{ }^{\circ} \mathrm{C}$ for $1 \mathrm{~h}$ to eliminate water, and then cooled to room 
temperature. The catalyst was then heated to $700{ }^{\circ} \mathrm{C}$ (ramp rate of $5{ }^{\circ} \mathrm{C} / \mathrm{min}$ ) under $(4 \%) \mathrm{H}_{2} / \mathrm{Ar}$ at a flow rate of $50 \mathrm{sccm}$ separately.

\section{Operando reaction}

Operando XAS measurements furfural reduction was also conducted at beamline MRCAT-10ID at the APS. The reactor was made of glassy carbon, and more details about the operando reactor can be found in the previous work did by Kispersky et. al. ${ }^{17} \mathrm{Cu}-\mathrm{K}$ edge XAS spectra were collected in transmission mode and each spectrum took about 1.5 minutes of scanning. About 4-5 spectra were merged to make one final spectrum. $17 \mathrm{mg}$ of Cu-chromite was mixed with $500 \mathrm{mg} \mathrm{SiC}$ and put into the reactor for operando reaction testing, while $100 \mathrm{mg}$ ALD Cu-chromite-45c-700 was added to the operando reactor for comparison based on the total activity for these two catalysts. The catalyst was first reduced at $200{ }^{\circ} \mathrm{C}$ for $30 \mathrm{~min}$ using 60 sccm $50 \% \mathrm{H}_{2} / \mathrm{He}(\mathrm{v} / \mathrm{v})$, the operando XAFS spectrum was collected and named ' $200{ }^{\circ} \mathrm{C}_{2}$ '. Furfural was then added through a bubbler preheated to $65^{\circ} \mathrm{C}$. This XAFS spectrum was named '200 ${ }^{\circ} \mathrm{C}$ Fur'. After GC analysis of the reaction performance, the furfural was switched off. The catalyst temperature was then increased to $300{ }^{\circ} \mathrm{C}$ and reduced in $\mathrm{H}_{2}$ while holding at this temperature for $30 \mathrm{~min}$. After lowering the temperature to $200{ }^{\circ} \mathrm{C}$, furfural was introduced into the reactor for a second time. The reaction performance of this catalyst after $300{ }^{\circ} \mathrm{C}$ reduction was collected and the operando XAFS spectrum was named ' $300{ }^{\circ} \mathrm{C}$ Fur'. The reaction performance and the XAFS spectrum of this catalyst after $400{ }^{\circ} \mathrm{C}$ reduction $\left({ }^{\circ} 400{ }^{\circ} \mathrm{C}\right.$ Fur') were collected in the same way. $\mathrm{Cu}$ XAFS spectra were recorded continuously during the catalytic experiments. It should be noted that all the reaction performance data was collected at $200{ }^{\circ} \mathrm{C}$.

Transmission electron microscopy (TEM) 
The TEM measurements were performed on a FEI Titan 80-300 S/TEM spectroscopy.

\section{Results}

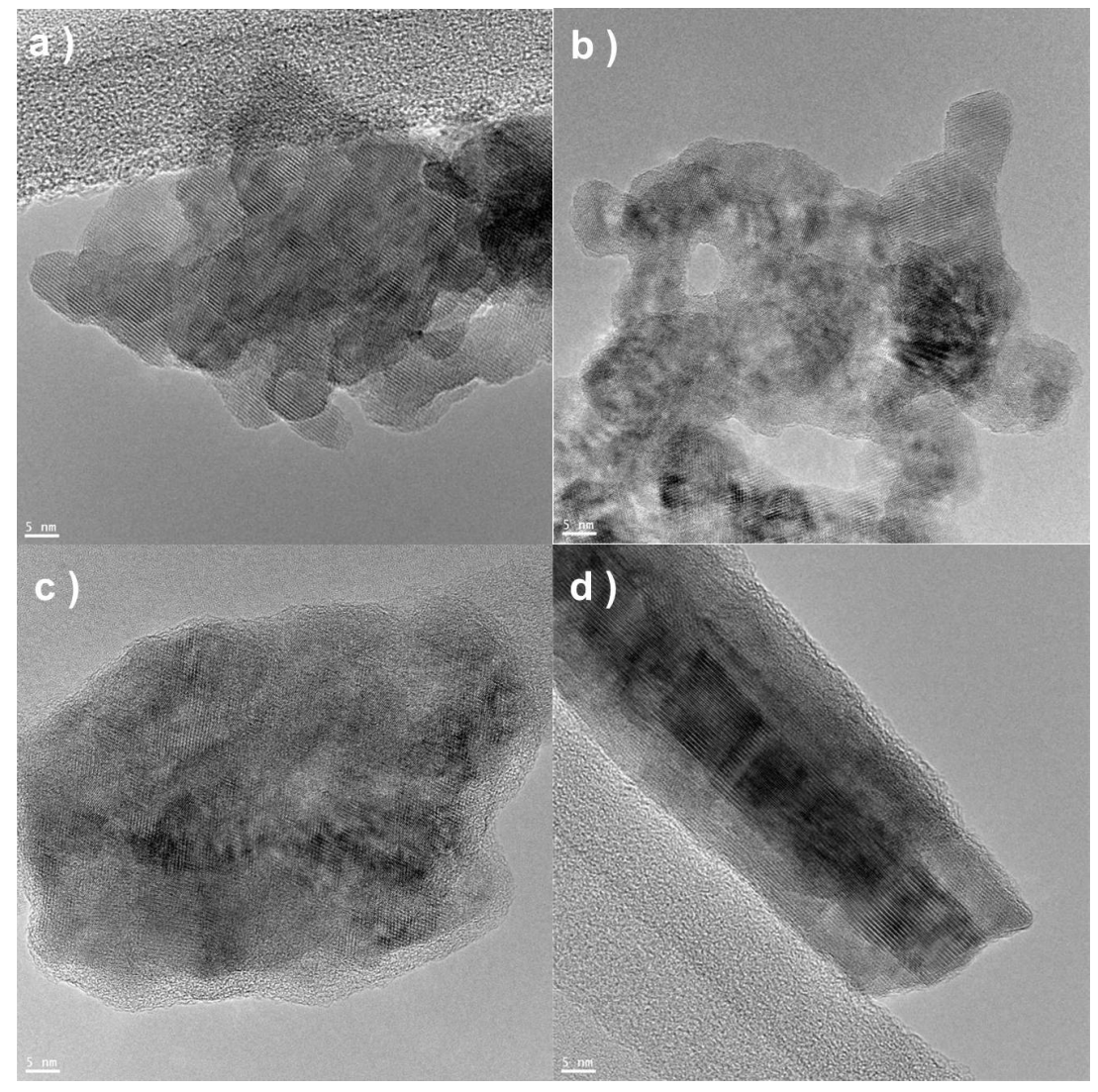

Figure 1. TEM images of (a) Cu-chromite, (b) ALD Cu-chromite-10c-700, (c) ALD Cuchromite-20c-700 and (d) ALD Cu-chromite-45c-700; (scale bars are 5nm).

Figure 1 shows TEM images of (a) Cu-chromite, (b) ALD Cu-chromite-10c-700, (c) ALD Cu-chromite-20c-700 and (d) ALD Cu-chromite-45c-700. From the scans across the TEM images, it is clear that $\mathrm{Cu}$-chromite is well crystallized both before and after the ALD overcoating treatment. No amorphous polymorph is visible on the surface of $\mathrm{Cu}$-chromite before the $\mathrm{Al}_{2} \mathrm{O}_{3}$ ALD. Careful inspection of the TEM image recorded for the sample with 10 cycles of 
ALD overcoating (ALD Cu-chromite-10c-700, Figure 1b) reveals a thin amorphous coating with an average thickness of $1.4 \mathrm{~nm}$. This value matches well with the expected thickness after 10 ALD $\mathrm{Al}_{2} \mathrm{O}_{3}$ cycles: $1.3 \mathrm{~nm}$. After 20 cycles of ALD overcoating, the average thickness of the ALD layer is $\sim 2.3 \mathrm{~nm}$, in good agreement with the expected thickness of $\sim 0.1 \mathrm{~nm} /$ cycle increment shown on Table 1. The overcoating thickness appeared to vary for different locations on the nanoparticles. This apparent non-uniformity may result from different TEM focusing conditions across the sample. Alternatively, the $\mathrm{ALD} \mathrm{Al}_{2} \mathrm{O}_{3}$ might nucleate differently on different crystalline planes of the $\mathrm{Cu}$ chromate. This phenomenon has been seen previously for $\mathrm{SiO}_{2} \mathrm{ALD}$ on $\mathrm{BN}$ nanoparticles where the $\mathrm{SiO}_{2}$ deposited only on the edges but not on the basal plane of the $\mathrm{BN}^{18}$. The thickness of the amorphous alumina became even thicker when 45 cycles of ALD overcoating used (Figure 1d). The non-uniformity of the $\mathrm{ALD} \mathrm{Al}_{2} \mathrm{O}_{3}$ is especially apparent in this image. The average thickness for the different overcoating cycles are shown in Table 1. Both the average thickness and the ranges of the thickness increase along with increasing number of cycles. The weight gain is not linear with increasing number of cycles probably due to blocking of surface sites with increasing number of ALD cycles. The $\mathrm{N}_{2}$ adsorption/desorption isotherms of uncovered and ALD overcoated catalysts as well as their corresponding pore size distributions are included in supporting information. (Figure S1)

Table 1: Range of the thickness values, average thickness, and weight gain of ALD layers for different cycles of ALD overcoatings;

\begin{tabular}{cccc}
\hline Catalyst & $\begin{array}{c}\text { Thickness range } \\
(\mathbf{n m})\end{array}$ & $\begin{array}{c}\text { Average thickness } \\
(\mathbf{n m})\end{array}$ & Weight gain (wt\%) \\
\hline Cu-chromite & 0 & 0 & 0 \\
\hline ALD Cu-chromite-10c-700 & $0.7-1.8$ & 1.4 & 12.5 \\
ALD Cu-chromite-20c-700 & $1.5-3.5$ & 2.3 & 23.5 \\
ALD Cu-chromite-45c-700 & $1.9-6.6$ & 3.6 & 42 \\
\hline
\end{tabular}



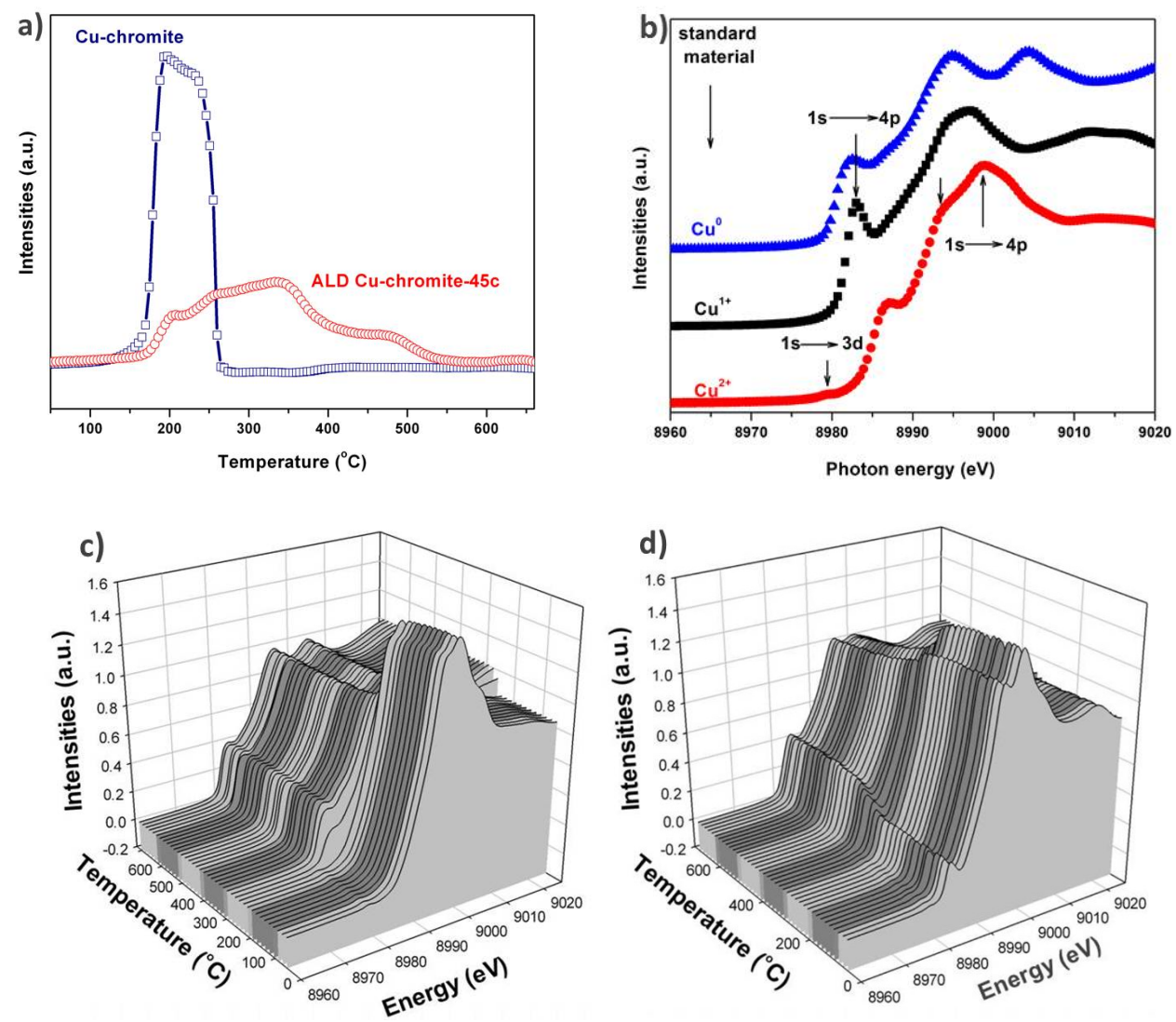

Figure 2 (a) TCD signal trace during the $\mathrm{H}_{2}$-TPR of $\mathrm{Cu}$-chromite and ALD Cu-chromite-45c-700 in $4 \% \mathrm{H}_{2} / \mathrm{Ar}$ at $5^{\circ} \mathrm{C} / \mathrm{min}$; (b) XANES spectra of standard $\mathrm{Cu}^{2+}, \mathrm{Cu}^{1+}$ and $\mathrm{Cu}^{0}$; stacked normalized $\mathrm{Cu}$ K-edge XANES spectra of (c) Cu-chromite and (d) ALD Cu-chromite-45c-700 collected during the in situ $\mathrm{H}_{2}$-TPR experiment.

Figure 2a shows the $\mathrm{H}_{2}$-TPR profile for the $\mathrm{Cu}$-chromite and ALD $\mathrm{Cu}$-chromite-45c-700 samples. The uncoated $\mathrm{Cu}$-chromite can be fully reduced to $\mathrm{Cu}^{0}$ below $250{ }^{\circ} \mathrm{C}$, much lower than the $\mathrm{Cu}$ catalyst modified by 45 cycles of alumina ALD layers. After ALD overcoating, the TPR reduction profile of $\mathrm{Cu}\left(\mathrm{ALD} \mathrm{Cu}\right.$-chromite-45c-700) is very broad. As shown in Figure $2 \mathrm{a}, \mathrm{Cu}^{2+}$ 
is not fully reduced to $\mathrm{Cu}^{0}$ until $550{ }^{\circ} \mathrm{C}$, which is observed in the TPR profile of ALD $\mathrm{Cu} / \gamma$ $\mathrm{Al}_{2} \mathrm{O}_{3}-45 \mathrm{c}$ (45 cycles of alumina ALD overcoating against $\gamma$-alumina supported copper catalyst) and $\mathrm{Cu}$ aluminate (made from calcination of $\mathrm{Cu} / \gamma-\mathrm{Al}_{2} \mathrm{O}_{3}$ at $700{ }^{\circ} \mathrm{C}$ for $5 \mathrm{~h}, \mathrm{Cu} / \gamma-\mathrm{Al}_{2} \mathrm{O}_{3}$ was bought from Sigma-Aldrich) shown in the supporting information (Figure S2a). The formation of $\mathrm{Cu}$ aluminate by calcination of $\mathrm{Cu} / \gamma-\mathrm{Al}_{2} \mathrm{O}_{3}$ was determined by XRD detection shown in the supporting information, too (Figure S2b). Complete reduction of the ALD $\mathrm{Cu} / \gamma-\mathrm{Al}_{2} \mathrm{O}_{3}-45 \mathrm{c}$ sample occurs at a temperature above $500{ }^{\circ} \mathrm{C}$. This demonstrates that ALD overcoatings dramatically affect the reduction temperature (chemistry) of the underlying nanoparticles. Dumesic and coworkers ${ }^{7}$ also found that $\mathrm{Cu}$ is partially oxidized in the presence of the alumina overcoating layers, but the mechanism is still unclear.

In situ XAFS measurements were undertaken next to determine the effect of $\mathrm{ALD} \mathrm{Al}_{2} \mathrm{O}_{3}$ overcoatings on the underlying $\mathrm{Cu}$ nanoparticles. XAFS measurements at the $\mathrm{Cu} \mathrm{K}$-edge were collected on three reference samples as shown in Figure $2 \mathrm{~b}$ : $\mathrm{CuO}\left(\mathrm{red}, \mathrm{Cu}^{2+}\right.$ ), cuprous oxide $\left(\mathrm{Cu}_{2} \mathrm{O}\right)$ (black, $\left.\mathrm{Cu}^{1+}\right)$ and $\mathrm{Cu}$ foil (blue, $\left.\mathrm{Cu}^{0}\right)$. The $\mathrm{Cu}^{2+}$ spectrum has a small pre-edge peak at a higher energy compared to the $\mathrm{Cu}^{1+}$, which shows the largest pre-edge feature. The edge energy for the $\mathrm{Cu}^{0}$ is shifted to even lower energy from around 8.99 to $9.01 \mathrm{keV}$. The differences between these reference spectra imply that the main oxidation state of the copper in the catalyst can be identified based on the overall features, the pre-edge positions and the height of the preedge peaks. ${ }^{16,19}$

Figure 2c-d shows a normalized stacked plot of the $\mathrm{Cu}$ K-edge XANES of (c) Cu-chromite and (d) ALD Cu-chromite-45c-700 collected during the in situ XAFS/ $\mathrm{H}_{2}-\mathrm{TPR}$ experiment. The XANES features for the ALD Cu-chromite-45c-700 (two peaks above the absorption edge and higher intensity for the second peak) are different from that of $\mathrm{Cu}$-chromite (only a single peak 
above the absorption edge), neither does $\mathrm{Cu}$ nor $\mathrm{CuOx}$ (Figure 3b). The overcoated sample is similar to copper aluminate. ${ }^{20}$ Previous workers have found that copper aluminate can easily be synthesized from $\mathrm{Cu} / \mathrm{Al}_{2} \mathrm{O}_{3}$ by heating to $>700{ }^{\circ} \mathrm{C}$, similar to our pre-treatment conditions ( 700 ${ }^{\circ} \mathrm{C}$ ) for the ALD Cu-chromite-45c-700. Comparing the XANES spectra for Cu-chromite and ALD Cu-chromite-45c-700 prior to reduction shows that they are similar to the $\mathrm{Cu}^{2+}$ reference spectrum. We therefore propose that a thin layer forms at the interface between the $\mathrm{ALD} \mathrm{Al}_{2} \mathrm{O}_{3}$ and the $\mathrm{Cu}$ nanoparticles. The existence of the pre-edge peak of ALD Cu-chromite- $45 \mathrm{c}-700$ prior to reduction further demonstrates that a new phase forms after the ALD overcoating. The XANES pre-edge features are highly sensitive to the local symmetry of the absorbing atom; ${ }^{21}$ there is no pre-edge peak for $\mathrm{Cu}$-chromite sample before reduction. In addition, the reduction of ALD Cu-chromite-45c-700 occurs over a wider temperature range compared to the $\mathrm{Cu}$-chromite. It is observed that $\mathrm{Cu}$-chromite is reduced from $\mathrm{Cu}^{2+}$ to $\mathrm{Cu}^{0}$ in a narrow temperature range between $200-300^{\circ} \mathrm{C}$ (Figure 2c). In contrast, the ALD overcoated catalyst (ALD Cu-chromite$45 \mathrm{c}-700$ ) was not completely reduced until about $650{ }^{\circ} \mathrm{C}$, in agreement with the ex situ $\mathrm{H}_{2}$-TPR measurement (Figure 2a). This provides further evidence for the formation of copper aluminate at the interface, with the copper aluminate increasing the reduction temperature of the underlying $\mathrm{Cu}^{20 b}, 22$ The characteristic spectral features of $\mathrm{Cu}^{2+}, \mathrm{Cu}^{+}$and $\mathrm{Cu}^{0}$ were evident in the pre-edge region. ${ }^{16,19}$ The small nano-pores ${ }^{8}$ formed within the ALD layers after heat-treatment may restrict the diffusion of feed and products to/from the $\mathrm{Cu}$ nanoparticles and may also influence the reduction temperature of $\mathrm{Cu}$ covered by ALD layers. 


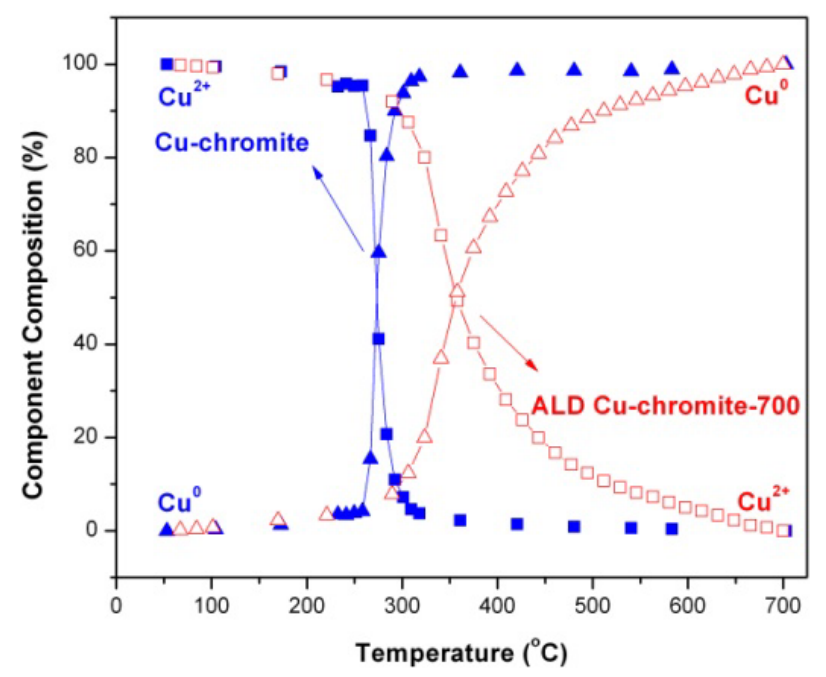

Figure 3. Percent of the different $\mathrm{Cu}$ species as a function of temperature during in situ $\mathrm{H}_{2}$-TPR from XANES data by Factor Analysis over Cu-chromite and ALD Cu-chromite-45c-700;

XANES linear combination fitting of the in situ XAFS/ $\mathrm{H}_{2}-\mathrm{TPR}$ measurements (Figure 2c-d) reveals the evolution of the two components: $\mathrm{Cu}^{2+}$ and $\mathrm{Cu}^{0}$ as a function of temperature (Figure 3). No $\mathrm{Cu}^{1+}$ species was observed, which suggests that the reduction of $\mathrm{Cu}^{1+}$ to $\mathrm{Cu}^{0}$ is faster than the reduction of $\mathrm{Cu}^{2+}$ to $\mathrm{Cu}^{1+} \cdot{ }^{16,19}$ The temperature for the $50 \%$ reduction was $\sim 100^{\circ} \mathrm{C}$ higher for the ALD overcoated catalyst, and the temperature for complete reduction was more than $300{ }^{\circ} \mathrm{C}$ higher than the uncoated material. This quantitative analysis provides further evidence that the $\mathrm{Cu}$ reduction was modified by the $\mathrm{ALD} \mathrm{Al}_{2} \mathrm{O}_{3}$ overcoating. FT-XAFS spectra (Figure S3a-b) also showed that the reduction temperature of ALD Cu-chromite- $45 \mathrm{c}-700$ was increased by about $300{ }^{\circ} \mathrm{C}$. There also is a smaller amount of $\mathrm{Cu}$ agglomeration for the ALD overcoated catalyst based on a comparison of the FT-XAFS spectra than bare Cu-chromite.

Both the ex-situ and in-situ $\mathrm{H}_{2}$ TPR experiments demonstrate that ALD overcoatings dramatically affect the reduction temperature (chemistry) of the underlying nanoparticles. The reduction temperature for $45 \mathrm{c}$ alumina ALD catalyst is about $300{ }^{\circ} \mathrm{C}$ higher than the non-coated catalyst. This could be because the small nano-pores ${ }^{8}$ formed within the ALD layers after heat- 
treatment which may restrict the diffusion of feed and products to/from the $\mathrm{Cu}$ nanoparticles. $\mathrm{Cu}$ aluminate formation could also influence the reduction property of $\mathrm{Cu}$. The reduction of $\mathrm{Cu}$ before or after $\mathrm{ALD}$ overcoatings was from $\mathrm{Cu}^{2+}$ to $\mathrm{Cu}^{0} ; \mathrm{Cu}^{1+}$ is barely seen during this reduction.

Table 2. In situ XAFS/ $\mathrm{H}_{2}-\mathrm{TPR}$ parameters comparison between different layers of ALD overcoating based on $\mathrm{Cu}$-XANES spectra (shown in figure $\mathrm{S} 4$ );

\begin{tabular}{|c|c|c|c|c|}
\hline & $\begin{array}{c}\mathrm{T}- \\
\text { onset( }\left({ }^{\circ} \mathrm{C}\right)\end{array}$ & $\begin{array}{c}\mathrm{T}- \\
\text { middle }\left({ }^{\circ} \mathrm{C}\right)\end{array}$ & $\begin{array}{c}\mathrm{T}- \\
\text { completion }\left({ }^{\circ} \mathrm{C}\right)\end{array}$ & $\begin{array}{c}\mathrm{Cu}^{1+} \text { percentage at } \mathrm{T}-\mathrm{mid} \\
(\%)\end{array}$ \\
\hline Cu-chromite & 250 & 275 & 308 & 0 \\
\hline $\begin{array}{l}\text { ALD Cu-chromite-10c- } \\
700\end{array}$ & 210 & 325 & 640 & 20 \\
\hline $\begin{array}{l}\text { ALD Cu-chromite-20c- } \\
700\end{array}$ & 212 & 354 & 640 & 12 \\
\hline $\begin{array}{c}\text { ALD Cu-chromite-30c- } \\
700\end{array}$ & 220 & 350 & 641 & 0.4 \\
\hline $\begin{array}{c}\text { ALD Cu-chromite-45c- } \\
700\end{array}$ & 215 & 352 & 650 & 0 \\
\hline
\end{tabular}

The modification of the metal particles creadited by the ALD overcoatings can be further understood by examining the changes in the XAFS spectra with different number of ALD overcoating cycles (Figure S4). Table 2 summarizes the reduction parameters obtained from the different ALD overcoated catalysts. The reduction onset temperatures are similar between the catalysts with and without ALD overcoatings. The temperature for complete reduction of the uncoated $\mathrm{Cu}$-chromite is $308{ }^{\circ} \mathrm{C}$ while all of the ALD modified catalysts are not completely reduced until $\sim 640{ }^{\circ} \mathrm{C}$. The temperature when $50 \%$ of the $\mathrm{Cu}$ is reduced (T-middle) are almost the same for all the ALD coated catalysts, about $75^{\circ} \mathrm{C}$ higher than uncoated Cu-chromite catalysts. However, the concentration of $\mathrm{Cu}^{1+}$ at T-mid is strongly dependent on the number of ALD overcoating cycles. From the XANES linear combination fittings it can be seen that the thinner overcoating layers exhibit a higher percentage of the $\mathrm{Cu}^{1+}$ species at $\mathrm{T}$-mid. The difference in the $\mathrm{Cu}^{1+}$ concentrations may be because the different layers of ALD overcoatings create different pore distributions following heat treatment. Thinner layer may have smaller 
pores within the layers which can limit the diffusion of $\mathrm{H}_{2}$ and $\mathrm{H}_{2} \mathrm{O}$ to and from the copper surface. The concentration of the reactant or the product changes the observed reduction temperature of $\mathrm{Cu}$ (Figure 2c-d and figure 3) Therefore reduction of $\mathrm{Cu}^{2+}$ to $\mathrm{Cu}^{1+}$ and $\mathrm{Cu}^{1+}$ to $\mathrm{Cu}^{0}$ were both inhibited for the thinner coatings. A larger percentage of $\mathrm{Cu}^{1+}$ can be identified on ALD Cu-chromite-10c-700 after heat-treatment in figure S4a, suggesting that a larger percentage of $\mathrm{CuAlO}_{2}$ is formed.
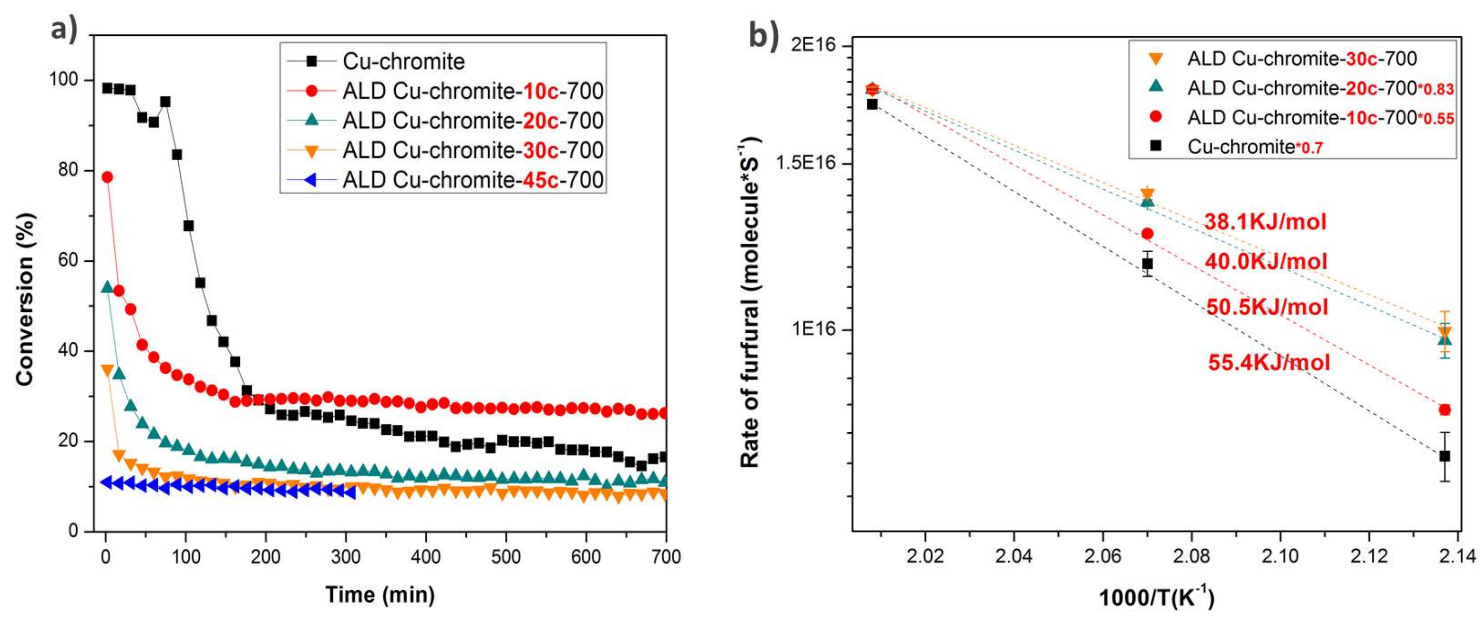

Figure 4. (a) Selective hydrogenation of furfural over copper chromite, ALD Cu-chromite-10c700, ALD Cu-chromite-20c-700, ALD Cu-chromite-30c-700 and ALD Cu-chromite-45c-700; (b) Arrhenius plots for furfural hydrogenation over Cu-chromite, ALD Cu-chromite-10c-700, ALD Cu-chromite-20c-700 and ALD Cu-chromite-30c-700, all the reaction rates were normalized to the same initial value.

Since ALD overcoatings can change the reduction temperatures of the underlying $\mathrm{Cu}$, the coating thickness should also influence the catalytic activity. To test this hypothesis, furfural hydrogenation reaction kinetic data were collected on $\mathrm{Cu}$-chromite, ALD Cu-chromite-10c-700, ALD Cu-chromite-20c-700, ALD Cu-chromite-30c-700 and ALD Cu-chromite-45c-700 in the vapor phase. Figure $4 \mathrm{a}$ shows the furfural conversion as a function of time-on-stream over the 
different catalysts. For these measurements, the catalysts were first reduced in situ using $10 \% \mathrm{H}_{2}$ for 1 hour at $200{ }^{\circ} \mathrm{C}$. All catalytic reactions were run at the same temperature $\left(200^{\circ} \mathrm{C}\right)$. The carbon balance stayed constant throughout the reaction process (about $98 \% \pm 2 \%$ ) indicating that almost all of the reaction products were accounted for. Two products were detected from the reactor effluent: furfuryl alcohol (the desired product) and 2-methyl furan (a known by-product). This result is consistent with literature reports indicating that dehydration of furfuryl alcohol forms 2-methyl furan. The selectivities to furfuryl alcohol were over $95 \%$ for all five catalysts. (Table S1) The lower the activity for furfural hydrogenation was the higher the selectivity to furfuryl alcohol would be, in good agreement with our previous studies. ${ }^{23}$ Severe catalyst deactivation was observed for the commercial $\mathrm{Cu}$-chromite. ${ }^{24}$ Furfural conversion dropped from $100 \%$ initially to $30 \%$ within 3 hours. This differs from previous results ${ }^{6}$ because smaller WHSV $\left(17 \mathrm{~h}^{-1}\right.$ rather than $52 \mathrm{~h}^{-1}$ in the literature $\left.{ }^{6}\right)$ was used for a better comparison between $\mathrm{Cu}-$ chromite and ALD overcoating catalyst after stabilization. The most active ALD catalyst following ALD overcoating is the one with only 10 cycles of alumina.

Catalyst deactivation is a major problem limiting the application of copper chromite in furfural hydrogenation. Both coke formation and chromite migration lead to blocking of the active sites of $\mathrm{Cu}$, and are the main causes for deactivation. ${ }^{6}$ This work showed that copper sintering (based on FT-XAFS shown in figure S3) is not a big problem for this catalyst most likely because the $\mathrm{Cu}$ loading of the $\mathrm{Cu}$-chromite is high (about $38 \mathrm{wt} \%$ ). Previous work has shown that the $\mathrm{Cu}$ particles are very large (103 nm based on XRD characterization), so any sintering that occurs is not a big problem for this system. ${ }^{6}$

Analogous to $\mathrm{ALD} \mathrm{Al}_{2} \mathrm{O}_{3}$-coated Pd catalysts for oxidative dehydrogenation of ethylene ${ }^{8}$, different cycles of $\mathrm{ALD}-\mathrm{Al}_{2} \mathrm{O}_{3}$ were coated over $\mathrm{Cu}$-Chromite to minimize the deactivation of 
this reaction. All of the ALD overcoated catalysts showed improved stability for furfural hydrogenation compared to the uncoated $\mathrm{Cu}$-chromite. The catalytic activities decreased with increasing $\mathrm{ALD} \mathrm{Al}_{2} \mathrm{O}_{3}$ coating thickness. However, the ALD coated catalysts also remained more active with time on stream. For instance, after $12 \mathrm{hr}$ on stream, the activity for the $10 \mathrm{c}$ sample was almost the same as that of the Cu-chromite catalyst (if the WHSVs were the same). The stability of the ALD Cu-chromite-10c-700 is much higher than that of the Cu-chromite. More interestingly, when 45 cycles was applied, there is almost no deactivation within $5 \mathrm{~h}$ 's run. Furthermore, there is no deactivation at the beginning of the reaction. The selectivity for all of the ALD catalysts is higher than $97 \%$ after stabilization, which is better than that of the $\mathrm{Cu}-$ chromite catalyst (92\%). Since there can be no leaching of $\mathrm{Cu}$ for the vapor phase reaction versus the liquid phase ${ }^{7}$ the ALD Cu-chromite catalysts shows potential for further application. The improved stability of the ALD catalysts may be due to the unique microporosity properties within the $\mathrm{ALD} \mathrm{Al}_{2} \mathrm{O}_{3}$ layers, which has proven to be effective for minimizing coke formation, as proposed by $\mathrm{Lu}$ and co-workers. ${ }^{8}$ They found that after high temperature treatment, the alumina overcoats preferentially segregated onto step edges and surface defect sites on the Pd nanoparticle surfaces, which are believed to attack $\mathrm{C}-\mathrm{C}$ bonds leading to coke formation. They also proposed that the micropores generated by heating the $\mathrm{ALD} \mathrm{Al}_{2} \mathrm{O}_{3}$ film exposed the $\mathrm{Pd}(111)$ facet which selectively attacked $\mathrm{C}-\mathrm{H}$ bonds producing ethylene. ${ }^{9}$ The copper aluminate formation may also influence the stability of our $\mathrm{Cu}$ catalyst. Because both the copper aluminate and the $\mathrm{ALD} \mathrm{Al}_{2} \mathrm{O}_{3}$ may minimize chromite migration over the top of the copper, the active sites should remain accessible to the feed and remain active even after prolonged operation. ${ }^{6}$

Figure $4 \mathrm{~b}$ shows Arrhenius plots for furfural hydrogenation over $\mathrm{Cu}$-chromite, ALD $\mathrm{Cu}$ chromite-10c-700, ALD Cu-chromite-20c-700 and ALD Cu-chromite-30c-700; all reaction rates 
were normalized to the same initial value. These data show that the activation energy for furfural hydrogenation over $\mathrm{Cu}$-chromite $(55.4 \mathrm{KJ} / \mathrm{mol})$ was reduced with increasing $\mathrm{Al}_{2} \mathrm{O}_{3}$ overcoating thickness. This may be related to the different concentrations of $\mathrm{Cu}^{2+}, \mathrm{Cu}^{1+}$ and $\mathrm{Cu}^{0}$ between the ALD catalysts and the bare $\mathrm{Cu}$-chromite catalyst after reduction at $200^{\circ} \mathrm{C}$ (based on $\mathrm{H}_{2}$-TPR results). Furfural conversion may have a different activation energy depending on the oxidation state of the $\mathrm{Cu}$. The furfural activation energy on copper nanoparticles shown here is similar to that of $\mathrm{Cu}$ on activated carbon ${ }^{25}$, while the activation energy is slightly lower than reported for a CuMgAl catalyst. ${ }^{26}$ Our results are in good agreement with previous work on the activation energy of furfural hydrogenation over $\mathrm{Cu}$-chromite at low temperature $(413 \mathrm{~K})$ but high $\mathrm{H}_{2}$ pressure (720Torr) by Rao et. al., which is about $50 \mathrm{KJ} / \mathrm{mol}^{5}$
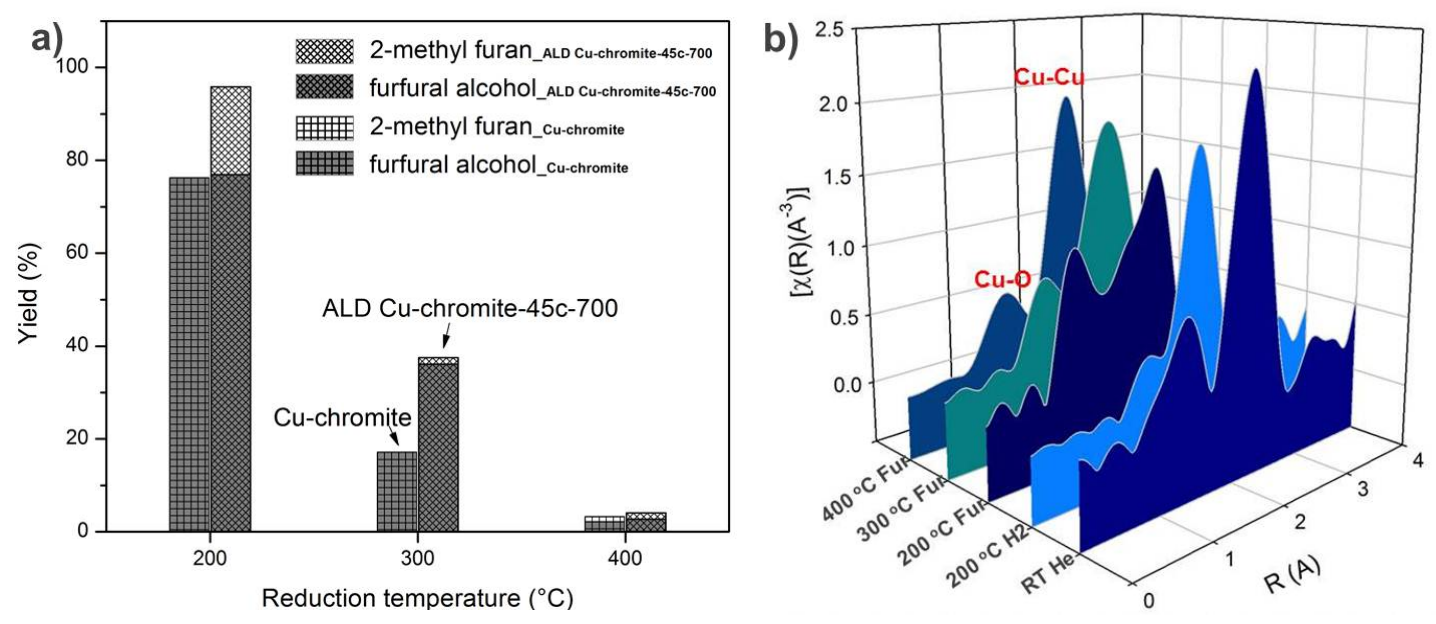

Figure 5(a), operando furfural reduction reaction performance under different reduction temperatures over $\mathrm{Cu}$-chromite and ALD Cu-chromite-45c-700; (b) Cu EXAFS spectra of the working catalyst (ALD Cu-chromite-45c-700) before (RT He), after reduction at $200{ }^{\circ} \mathrm{C}\left(200{ }^{\circ} \mathrm{C}\right.$ $\mathrm{H}_{2}$ ) and during furfural reduction reactions $\left(200{ }^{\circ} \mathrm{C}\right.$ Fur), higher reduction temperatures were also applied here $\left(300^{\circ} \mathrm{C}\right.$ Fur and $400{ }^{\circ} \mathrm{C}$ Fur $)$. All the reactions were carried out at $200{ }^{\circ} \mathrm{C}$. 
Operando XAFS characterization was performed on the ALD Cu-chromite-45c-700 to elucidate the active species of the working catalyst. The performance of the $\mathrm{Cu}$-chromite under identical conditions is shown in Figure 5a. The catalysts were reduced at different temperatures, while the catalytic performance shown here were collected at $200{ }^{\circ} \mathrm{C}$. As shown in Figure 5(a), after $200{ }^{\circ} \mathrm{C}$ reduction, the ALD Cu-chromite- $45 \mathrm{c}-700$ shows $96 \%$ activity with about $80 \%$ furfuryl alcohol selectivity. (The activity was obtained from the yield of furfuryl alcohol plus 2methyl furan at nearly $100 \%$ carbon balance of this reaction while the selectivity was determined from the yield of each product.) As the reduction temperature increased, the activity of the ALD Cu-chromite-45c-700 decreased. For example, the activity of the ALD Cu-chromtie-45c-700 drops to $40 \%$ after reduction at $300^{\circ} \mathrm{C}$, which means that the ALD Cu-chromtie- $45 \mathrm{c}-700$ loses $50 \%$ activity by simply increasing the reduction temperature from $200^{\circ} \mathrm{C}$ to $300^{\circ} \mathrm{C}$. This activity loss is further increased by pre-reduction of the catalyst at $400^{\circ} \mathrm{C}$ with the ALD catalyst having near zero activity. The same trend of lower activity at higher pre-reduction temperatures can be seen in the uncoated $\mathrm{Cu}$-chromite catalyst (Figure 5a). From the selectivities of the ALD Cuchromite-45c-700, it can also be found that the higher the activity the lower the selectivity to furfuryl alcohol in good agreement with previous work. ${ }^{6}$ In addition coke formation is not expected to be a major problem for the ALD coated catalyst. As seen by Lu and co-workers, the ALD overcoating helps minimize coke formation over Pd overcoated catalysts carried out at over $600^{\circ} \mathrm{C}$ with ethylene as one of the products. ${ }^{8}$ We also found that there is almost no deactivation for the ALD catalyst in furfural reduction even after $12 \mathrm{hr}$ on stream. Chromite migration should be held back by 45 cycles of ALD overcoatings. Therefore we propose that loss of the active component may cause the reduction in activity with increasing reduction temperature. 
Figure $5 \mathrm{~b}$ shows the $\mathrm{Cu}$ EXAFS spectra of ALD Cu-chromite-45c-700 under reaction conditions at several temperatures. From the spectra, the $\mathrm{Cu}-\mathrm{O}$ coordination peak and $\mathrm{Cu}-\mathrm{Cu}$ coordination peak can be easily identified in agreement with previous work. ${ }^{27}$ Comparing the asprepared sample (RT He) with the reduced sample $\left(200^{\circ} \mathrm{C} \mathrm{H}_{2}\right)$, obvious signs of reduction can be seen. The $\mathrm{Cu}-\mathrm{O}$ peak is much smaller in the reduced sample as compared to the as-prepared sample. As furfural was introduced, the $\mathrm{Cu}-\mathrm{O}$ peak increased while the $\mathrm{Cu}-\mathrm{Cu}$ peak decreasesd, demonstrating that the $\mathrm{Cu}$ is being oxidized, and the EXAFS spectrum shows a mixture $\mathrm{Cu}^{1+}$ and $\mathrm{Cu}^{027}$ This finding is in good agreement with previous work by Rao and his co-workers, who showed that the furfural reduction activity correlates with the concentration of $\mathrm{Cu}^{1+}$ sites, which appear to be involved in the catalytic process. They also showed the necessity of $\mathrm{Cu}^{0}$ sites for catalytic activity. ${ }^{5}$ Therefore, the active species of the working catalyst $\left(200{ }^{\circ} \mathrm{C}\right.$ Fur $)$ is $\mathrm{Cu}^{1+} / \mathrm{Cu}^{0}$; neither $\mathrm{Cu}^{1+}$ nor $\mathrm{Cu}^{0}$ alone are sufficient for this ALD catalyst. Further increasing the reduction temperature decreased the $\mathrm{Cu}-\mathrm{O}$ peak intensity and and increased the intensity of the $\mathrm{Cu}-\mathrm{Cu}$ peak $\left(300{ }^{\circ} \mathrm{C} \mathrm{Fur} / 400{ }^{\circ} \mathrm{C}\right.$ Fur $)$. The ALD catalyst loses activity for furfural reduction at the same time: further evidence that the active catalyst has a combination of both $\mathrm{Cu}^{1+}$ and $\mathrm{Cu}^{0}$, consistent with our previous work. ${ }^{6}$

Furthermore, based on the difference between the EXAFS spectra ('200 ${ }^{\circ} \mathrm{C} \mathrm{H}_{2}$ ' vs. ' $200{ }^{\circ} \mathrm{C}$ Fur'), it is clear that the addition of furfural to the ALD Cu-chromite-45c-700 after reduction results in the formation of some oxygenates on the $\mathrm{Cu}$ surface. Therefore, some oxygen containing components are generated during the reaction, even though the catalyst was fully reduced to $\mathrm{Cu}^{0}$ prior to reaction. Further increasing the reduction temperature reduces the concentration of $\mathrm{Cu}$ oxygenates (Fig. 5b) while simultaneously reducing the furfural reduction activity (Fig. 5a). The EXAFS spectrum ' $200{ }^{\circ} \mathrm{C}$ Fur' is similar to $\mathrm{Cu}^{1+}$, while $\mathrm{Cu}^{2+}$ cannot exist 
stably under such a reducing atmosphere $\left(50 \% \mathrm{H}_{2}\right.$ plus $2 \%$ furfural) at $200{ }^{\circ} \mathrm{C}$. Therefore, we propose that both $\mathrm{Cu}^{1+}\left(\right.$ not $\left.\mathrm{Cu}^{2+}\right)$ and $\mathrm{Cu}^{0}$ are required for furfural hydrogenation in agreement with the previous work by Rao and co-workers. ${ }^{25}$ Since thinner ALD overcoating layers increase the $\mathrm{Cu}^{1+}$ concentration (Table 2), this may also explain why thinner ALD overcoating layers produce a higher furfural hydrogenation activity after stabilization (Figure 4a). In addition, a few cycles of alumina ALD coating block less active sites of ALD Cu-chromite-45c-700. The $\mathrm{Cu}^{1+}$ sites discussed here can be $\mathrm{Cu}_{2} \mathrm{O}$ or $\mathrm{CuAlO}_{2}$.

\section{Discussion}

Hydrogenation is a fundamental reaction in biomass conversion. ${ }^{2 \mathrm{~b}, \mathrm{c}}$ Furfural possesses both $\mathrm{C}=\mathrm{C}$ and $\mathrm{C}=\mathrm{O}$ bonds, and is a special kind of $\alpha, \beta$ unsaturated compound, because the $\mathrm{C}=\mathrm{C}$ stays within one 5 member ring and 6 electron stabilized system. This makes the $\mathrm{C}=\mathrm{C}$ bond very stable. The adsorption mode of furfural also influences the selectivity of the furfural hydrogenation, and $\mathrm{C}=\mathrm{O}$ is most likely adsorbed on the surface of $\mathrm{Cu}^{23}$ Therefore, the $\mathrm{C}=\mathrm{O}$ bond can be reduced most easily on $\mathrm{Cu}$ nanoparticles. However, one problem is that the initial product from furfural hydrogenation, furfuryl alcohol, can be further dehydrated to form 2-methyl furan. ${ }^{23}$ Consequently, a higher activity can result in a lower selectivity to furfuryl alcohol. ALD modification would seem to be a good way to block some of active sites on $\mathrm{Cu}$-chromite to suppress the activity while increasing selectivity to furfuryl alcohol.

ALD is a variation on chemical vapor deposition in which metals, oxides, and other materials are deposited on surfaces by a sequence of self-limiting reactions. The self-limiting character of these reactions makes it possible to achieve uniform deposits on high-surface-area porous solids. Therefore, design and synthesis of advanced catalysts on the nanoscale becomes possible 
through precise control over the structure and composition of the underlying support, the catalytic active sites, and the protective layer. Even if the catalytic nanopartical surfaces are initially fully covered by the ALD thin films, these surfaces can became accessible to reagent gases through pores formed in the overcoat as a result of high-temperature treatment. In addition, the ALD overcoat can preferentially segregated onto step edges and surface defects. These mechanisms might be responsible for the enhancement of the stability of the ALD coated $\mathrm{Cu}$ chromite catalysts in our study.

One might anticipate that the overcoating thickness would be critical to catalyst performance. If the coating is too thick, it might completely shut off the catalytic activity, but if it is too thin, then sintering and migration will not be inhibited. Here we found that fewer ALD layers (e.g. 10 cycles) showed higher furfural hydrogenation activity but lower catalyst stability. In contrast, the thicker ALD coatings (e.g. 45 cycles) exhibited lower activity but improved stability. This result differs from a previous study ${ }^{28}$ of methanol decomposition on overcoated Pd nanoparticles. Their study showed that a single $\mathrm{ALD} \mathrm{Al}_{2} \mathrm{O}_{3}$ cycle was sufficient to suppress sintering during methanol decomposition at $270{ }^{\circ} \mathrm{C}$ for $6 \mathrm{~h}$. Dumesic ${ }^{7}$ and coworkers found that 45 cycles alumina ALD overcoating can eliminate the deactivation of $\mathrm{Cu}$ caused by sintering and leaching of the metal under trickle bed conditions.

Coke formation may be another cause of deactivation of $\mathrm{Cu}$-chromite. A previous study ${ }^{6}$ showed coke formation on the surface of used $\mathrm{Cu}$-chromite based on XPS measurements, while there is no coke on the surface of a fresh catalyst. Recently, Lu et.al., ${ }^{8}$ found that the coke formation on Pd-NPs can be suppressed by 45 cycles alumina ALD overcoating. They speculated that the $\mathrm{Al}_{2} \mathrm{O}_{3}$ overcoat preferentially segregated onto step edges and surface defects that if exposed, are believed to break C-C bonds leading to coke formation. $\mathrm{CO}$ chemisorption ${ }^{28}$ was 
further applied to study how the ALD overcoating influences the molecule adsorption. No clear shifts of CO adsorption were observed for different cycles of ALD Pd catalysts. Therefore, we believe that there should not be typical electronic effect between alumina ALD layers and the underlying nanoparticle. Notwithstanding, the reduction temperature of $\mathrm{Cu}$ was increased dramatically. This could be due to formation of copper aluminate and micropores inside the ALD layers after heat-treatment; that will influence the transport of gas to or from the surface of $\mathrm{Cu}$. Changing the reduction temperature of $\mathrm{Cu}$ after ALD overcoating would change the composition of different copper species after reduction at $200{ }^{\circ} \mathrm{C}$ during the reaction. Perhaps this explains how ALD overcoating can lower the activation energy of furfural on $\mathrm{Cu}$.

$\mathrm{RaO}^{25}$ and coworkers found that the TOF of furfural hydrogenation over different $\mathrm{Cu}$ based catalysts decreased steadily as the fraction of surface $\mathrm{Cu}^{1+}$ sites decreased from 0.3 to zero (i.e., $100 \% \mathrm{Cu}^{0}$ ). Simple Langmuir-Hinshelwood models involving a bimolecular surface reaction as the rate-determining step described these data well and a two-site model, which could represent $\mathrm{Cu}^{0}$ and $\mathrm{Cu}^{1+}$ sites, is shown to very satisfactorily fit the data for all the catalysts surveyed. They propose that both $\mathrm{Cu}^{0}$ and $\mathrm{Cu}^{1+}$ are necessary species for the furfural reduction reaction. However, they did not identify the active species using any of characterization method. We use operando XAFS to study the active species of ALD Cu-chromite-45c-700 during furfural hydrogenation reaction. We found that $\mathrm{Cu}$ was first reduced nearly to $\mathrm{Cu}^{0}$ after reducing at 200 ${ }^{\circ} \mathrm{C}$. Then, furfural $/ \mathrm{H}_{2} / \mathrm{He}(\mathrm{v} / \mathrm{v} / \mathrm{v}: 1 / 25 / 25)$ was introduced to the reactor. The Cu catalyst was partially oxidized to $\mathrm{Cu}^{1+}$ at the same time. The active species for this reaction indeed appears to be $\mathrm{Cu}^{0}$ and $\mathrm{Cu}^{1+}$. As the reduction temperature was increased, the activity of furfural reduction decreased commensurate with the lower concentration of $\mathrm{Cu}^{1+}$, which is further evidence that $\mathrm{Cu}^{1+}$ and $\mathrm{Cu}^{0}$ both required active species for furfural hydrogenation. Moreover, $\mathrm{Cu}^{1+}$ may 
function as electrophilic or Lewis acid sites to polarize the $\mathrm{C}=\mathrm{O}$ bond via the electron lone pair on oxygen ${ }^{29}$, thus improving the reactivity of the carbonyl group in furfural. That is consistent with the behavior reported for crotonaldehyde hydrogenation on copper based catalysts. ${ }^{29 b, 30}$ Dandekar et al. ${ }^{29 \mathrm{~b}}$ have shown that significantly higher TOFs were observed on $\mathrm{Cu}$ dispersed on a nitric acid-treated activated carbon, and it is proposed that oxygen-containing acidic groups on the surface of this carbon enhance the activity by providing additional adsorption sites for crotonaldehyde that can react with hydrogen spilled over from $\mathrm{Cu}^{0}$ sites. Unusually low TOFs were exhibited by $\mathrm{Cu}$ deposited on the graphitized fibers by an ion exchange technique. ${ }^{29 \mathrm{~b}}$ Fridman and Davydov have reported that the oxidation state of $\mathrm{Cu}$ can affect not only the dehydrogenation activity but also the selectivity, and in their study of cyclohexanol dehydrogenation over $\mathrm{Cu}-\mathrm{Mg}$ and $\mathrm{Cu}-\mathrm{Zn}-\mathrm{Al}$ catalysts, they found that $\mathrm{Cu}^{1+}$ was significantly more active than $\mathrm{Cu}^{0}$ for cyclohexanone formation, while $\mathrm{Cu}^{0}$ was active for the aromatization reaction of cyclohexanol to phenol. ${ }^{31}$

\section{Conclusions}

Highly stable furfural reduction reaction performance of $\mathrm{CuCr}_{2} \mathrm{O}_{4} \cdot \mathrm{CuO}$ was achieved by applying $\mathrm{ALD} \mathrm{Al}_{2} \mathrm{O}_{3}$ overcoatings, which appears to decrease coke formation, sintering of $\mathrm{Cu}$ and coverage of the active copper by chromite migration. Furthermore, the alumina ALD overcoating increases the reduction temperature of $\mathrm{Cu}$ nanoparticles and lowers the activation energy of the furfural hydrogenation process. Thinner ALD layers exhibit higher furfural reduction activity. Finally, based on the operando reaction studies, $\mathrm{Cu}^{1+} / \mathrm{Cu}^{0}$ are both necessary and active species for the furfural reduction reaction.

\section{Acknowledgements}


This material is based upon work supported as part of the Institute for Atom-efficient Chemical Transformations (IACT), an Energy Frontier Research Center funded by the U.S. Department of Energy, Office of Science and Office of Basic Energy Sciences. Use of the Advanced Photon Source is supported by the U. S. Department of Energy, Office of Science, and Office of Basic Energy Sciences, under Contract DE-AC02-06CH11357. MRCAT operations are supported by the Department of Energy and the MRCAT member institutions. We thank Dr. Heng Shou for helpful discussions.

(*Notes: Airgas USA, LLC North Central Region 1250 W. Washington Street, West Chicago, IL 60185.)

\section{References}

1. Administration, U. S. E. I. Annual Energy Review. www.eia.gov/aer.

2. (a) Perlack, R. D.; (Leads), B. J. S., U.S. Billion-Ton Update: Biomass Supply for a Bioenergy and Bioproducts Industry. Energy, U. S. D. o., Ed. Oak Ridge National Laboratory: Oak Ridge, TN, 2011; p 227; (b) Huber, G. W.; Iborra, S.; Corma, A., Synthesis of transportation fuels from biomass: Chemistry, catalysts, and engineering. Chemical Reviews 2006, 106 (9), 4044-4098; (c) Alonso, D. M.; Bond, J. Q.; Dumesic, J. A., Catalytic conversion of biomass to biofuels. Green Chemistry 2010, 12 (9), 1493-1513.

3. Lange, J. P.; van de Graaf, W. D.; Haan, R. J., Conversion of Furfuryl Alcohol into Ethyl Levulinate using Solid Acid Catalysts. ChemSusChem 2009, 2 (5), 437-441.

4. Thomas, C. L., Catalytic Processes and Proven Catalysts. Academic Press, New York 1970.

5. Rao, R.; Dandekar, A.; Baker, R. T. K.; Vannice, M. A., Properties of copper chromite catalysts in hydrogenation reactions. Journal of Catalysis 1997, 171 (2), 406-419. 
6. Liu, D.; Zemlyanov, D.; Wu, T.; Lobo-Lapidus, R. J.; Dumesic, J. A.; Miller, J. T.; Marshall, C. L., Deactivation mechanistic studies of copper chromite catalyst for selective hydrogenation of 2-furfuraldehyde. Journal of Catalysis 2013, 299 (0), 336-345.

7. O'Neill, B. J.; Jackson, D. H. K.; Crisci, A. J.; Farberow, C. A.; Shi, F.; Alba-Rubio, A. C.; Lu, J.; Dietrich, P. J.; Gu, X.; Marshall, C. L.; Stair, P. C.; Elam, J. W.; Miller, J. T.; Ribeiro, F. H.; Voyles, P. M.; Greeley, J.; Mavrikakis, M.; Scott, S. L.; Kuech, T. F.; Dumesic, J. A., Stabilization of Copper Catalysts for Liquid-Phase Reactions by Atomic Layer Deposition. Angewandte Chemie International Edition 2013, 52 (51), 13808-13812.

8. Lu, J.; Fu, B.; Kung, M. C.; Xiao, G.; Elam, J. W.; Kung, H. H.; Stair, P. C., Coking- and Sintering-Resistant Palladium Catalysts Achieved Through Atomic Layer Deposition. Science 2012, 335 (6073), 1205-1208.

9. $\quad$ Lu, J.; Liu, B.; Greeley, J. P.; Feng, Z.; Libera, J. A.; Lei, Y.; Bedzyk, M. J.; Stair, P. C.; Elam, J. W., Porous Alumina Protective Coatings on Palladium Nanoparticles by Self-Poisoned Atomic Layer Deposition. Chemistry of Materials 2012, 24 (11), 2047-2055.

10. Wang, X.; Krommenhoek, P. J.; Bradford, P. D.; Gong, B.; Tracy, J. B.; Parsons, G. N.; Luo, T.-J. M.; Zhu, Y. T., Coating Alumina on Catalytic Iron Oxide Nanoparticles for Synthesizing Vertically Aligned Carbon Nanotube Arrays. Acs Applied Materials \& Interfaces 2011, 3 (11), 4180-4184.

11. Liang, X.; Li, J.; Yu, M.; McMurray, C. N.; Falconer, J. L.; Weimer, A. W., Stabilization of Supported Metal Nanoparticles Using an Ultrathin Porous Shell. Acs Catalysis 2011, 1 (10), $1162-1165$.

12. (a) Jun Lu, Y. L., Kah Chun Lau, Xiangyi Luo, Peng Du, Jianguo Wen, Rajeev S. Assary, Ujjal Das, Dean J. Miller, Jeffrey W. Elam, Hassan M. Albishri, D Abd El-Hady, 
Yang-Kook Sun, Larry A. Curtiss and Khalil Amine, A nanostructured cathode architecture for low charge overpotential in lithium-oxygen batteries. Nature Communications 2013; (b) Lei, Y.; Lu, J.; Luo, X.; Wu, T.; Du, P.; Zhang, X.; Ren, Y.; Wen, J.; Miller, D. J.; Miller, J. T.; Sun, Y.K.; Elam, J. W.; Amine, K., Synthesis of Porous Carbon Supported Palladium Nanoparticle Catalysts by Atomic Layer Deposition: Application for Rechargeable Lithium-O2 Battery. Nano Letters 2013, 13 (9), 4182-4189.

13. Pagán-Torres, Y. J.; Gallo, J. M. R.; Wang, D.; Pham, H. N.; Libera, J. A.; Marshall, C. L.; Elam, J. W.; Datye, A. K.; Dumesic, J. A., Synthesis of Highly Ordered Hydrothermally Stable Mesoporous Niobia Catalysts by Atomic Layer Deposition. ACS Catalysis 2011, 1 (10), 1234-1245.

14. J. W. Elam, M. D. G., and S. M. George, Viscous flow reactor with quartz crystal microbalance for thin film growth by atomic layer deposition. Rev. Sci. Instrum. 2002, 73 (8), 2981-2987.

15. Libera, J. A.; Elam, J. W.; Pellin, M. J., Conformal ZnO coatings on high surface area silica gel using atomic layer deposition. Thin Solid Films 2008, 516 (18), 6158-6166.

16. Neylon, M. K.; Marshall, C. L.; Kropf, A. J., In situ EXAFS analysis of the temperatureprogrammed reduction of Cu-ZSM-5. Journal of the American Chemical Society 2002, 124 (19), $5457-5465$.

17. Kispersky, V. F.; Kropf, A. J.; Ribeiro, F. H.; Miller, J. T., Low absorption vitreous carbon reactors for operando XAS: a case study on $\mathrm{Cu} /$ Zeolites for selective catalytic reduction of NOx by NH3. Physical Chemistry Chemical Physics 2012, 14 (7), 2229-2238. 
18. Ferguson, J. D.; Weimer, A. W.; George, S. M., Atomic layer deposition of SiO2 films on BN particles using sequential surface reactions. Chemistry of Materials 2000, 12 (11), 34723480.

19. (a) Castagnola, N. B.; Kropf, A. J.; Marshall, C. L., Studies of Cu-ZSM-5 by X-ray absorption spectroscopy and its application for the oxidation of benzene to phenol by air. Appl. Catal. A 2005, 290 (1-2), 110-122; (b) Castagnola, M. J.; Neylon, M. K.; Marshall, C. L., Coated bifunctional catalysts for NO, SCR with C3H6 - Part II. In situ spectroscopic characterization. Catal. Today 2004, 96 (1-2), 61-70.

20. (a) Yamamoto, T.; Tanaka, T.; Suzuki, S.; Kuma, R.; Teramura, K.; Kou, Y.; Funabiki, T.; Yoshida, S., NO reduction with $\mathrm{CO}$ in the presence of O-2 over $\mathrm{Cu} / \mathrm{Al} 2 \mathrm{O} 3$ (3) structural analysis of active species by means of XAFS and UV/VIS/NIR spectroscopy. Topics in Catalysis 2002, 18 (1-2), 113-118; (b) Alejandre, A.; Medina, F.; Salagre, P.; Correig, X.; Sueiras, J. E., Preparation and study of $\mathrm{Cu}-\mathrm{Al}$ mixed oxides via hydrotalcite-like precursors. Chemistry of Materials 1999, 11 (4), 939-948.

21. (a) Farges, F.; Brown, G. E.; Rehr, J. J., Ti K-edge XANES studies of Ti coordination and disorder in oxide compounds: Comparison between theory and experiment. Physical Review B 1997, 56 (4), 1809-1819; (b) Zhang, H.; Pan, X.; Liu, J.; Qian, W.; Wei, F.; Huang, Y.; Bao, X., Enhanced Catalytic Activity of Sub-nanometer Titania Clusters Confined inside Double-Wall Carbon Nanotubes. Chemsuschem 2011, 4 (7), 975-980.

22. Severino, F.; Brito, J. L.; Laine, J.; Fierro, J. L. G.; Agudo, A. L., Nature of copper active sites in the carbon monoxide oxidation on $\mathrm{CuAl} 2 \mathrm{O} 4$ and $\mathrm{CuCr} 2 \mathrm{O} 4$ spinel type catalysts. Journal of Catalysis 1998, 177 (1), 82-95. 
23. (a) Sitthisa, S.; Sooknoi, T.; Ma, Y.; Balbuena, P. B.; Resasco, D. E., Kinetics and mechanism of hydrogenation of furfural on $\mathrm{Cu} / \mathrm{SiO} 2$ catalysts. J. Catal. 2011, 277 (1), 1-13; (b) Sitthisa, S.; Resasco, D. E., Hydrodeoxygenation of Furfural Over Supported Metal Catalysts: A Comparative Study of Cu, Pd and Ni. Catalysis Letters 2011, 141 (6), 784-791; (c) Nagaraja, B. M.; Padmasri, A. H.; Raju, B. D.; Rao, K. S. R., Vapor phase selective hydrogenation of furfural to furfuryl alcohol over Cu-MgO coprecipitated catalysts. J. Mol. Catal. A 2007, 265 (1-2), 9097; (d) Zheng, H. Y.; Zhu, Y. L.; Teng, B. T.; Bai, Z. Q.; Zhang, C. H.; Xiang, H. W.; Li, Y. W., Towards understanding the reaction pathway in vapour phase hydrogenation of furfural to 2methylfuran. J. Mol. Catal. A 2006, 246 (1-2), 18-23.

24. Swadesh, S. Catalytic Production of Furfural Alcohol and Catalyst Therefore. 1956.

25. Rao, R. S.; Baker, R. T. K.; Vannice, M. A., Furfural hydrogenation over carbonsupported copper. Catalysis Letters 1999, 60 (1-2), 51-57.

26. Villaverde, M. M.; Bertero, N. M.; Garetto, T. F.; Marchi, A. J., Selective liquid-phase hydrogenation of furfural to furfuryl alcohol over Cu-based catalysts. Catalysis Today 2013, 213, 87-92.

27. Fox, E. B.; Velu, S.; Engelhard, M. H.; Chin, Y.-H.; Miller, J. T.; Kropf, J.; Song, C., Characterization of $\mathrm{CeO} 2$-supported $\mathrm{Cu}-\mathrm{Pd}$ bimetallic catalyst for the oxygen-assisted water-gas shift reaction. Journal of Catalysis 2008, 260 (2), 358-370.

28. Lu, J.; Elam, J. W.; Stair, P. C., Synthesis and Stabilization of Supported Metal Catalysts by Atomic Layer Deposition. Accounts of Chemical Research 2013, 46 (8), 1806-1815.

29. (a) Boronat, M.; May, M.; Illas, F., Origin of chemoselective behavior of S-covered $\mathrm{Cu}(111)$ towards catalytic hydrogenation of unsaturated aldehydes. Surface Science 2008, 602 
(21), 3284-3290; (b) Dandekar, A.; Baker, R. T. K.; Vannice, M. A., Carbon-supported copper catalysts II. Crotonaldehyde hydrogenation. Journal of Catalysis 1999, 184 (2), 421-439.

30. Rioux, R. M.; Vannice, M. A., Hydrogenation/dehydrogenation reactions: isopropanol dehydrogenation over copper catalysts. Journal of Catalysis 2003, 216 (1-2), 362-376.

31. Fridman, V. Z.; Davydov, A. A., Dehydrogenation of cyclohexanol on copper-containing catalysts I. The influence of the oxidation state of copper on the activity of copper sites. Journal of Catalysis 2000, 195 (1), 20-30. 


\section{Supporting Information:}
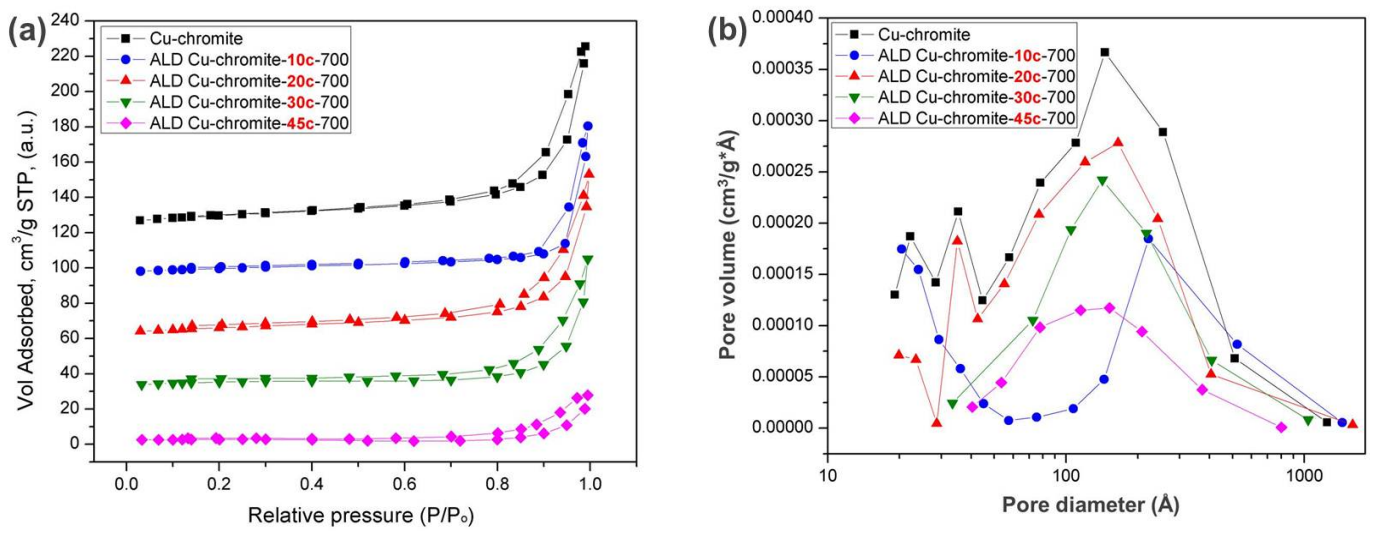

Figure $\mathrm{S} 1$ (a) $\mathrm{N}_{2}$ adsorption/desorption isotherms of $\mathrm{Cu}$-chromite, ALD Cu-chromite-10c-700, ALD Cu-chromite-20c-700, ALD Cu-chromite-45c-700 and (b) their corresponding pore size distributions from desorption branch (equilibrium transition).

Figure S1(a) shows the adsorption and desorption isotherms of nitrogen at $77 \mathrm{~K}$ for $\mathrm{Cu}-$ chromite, ALD Cu-chromite-10c-700, ALD Cu-chromite-20c-700 and ALD Cu-chromite-45c700 catalysts. From the shape of the isotherms, this is a typical type five isotherms. This type of isotherm is convex to $\mathrm{P} / \mathrm{P}_{0}$ axis at the low $\mathrm{P} / \mathrm{P}_{0}$ regin, then there is a pore condensation and hysteresis. There is no inflection point indicates the stage at which monolayer coverage is complete and multilayer adsorption begins to occur, indicates that the attractive adsorbateadsorbent interactions are relatively weak. The hysteresis loop is associated with the occurrence of pore condensation. The hysteresis loop obtained for uncoated and ALD overcoated catalysts spreads over a $\mathrm{P} / \mathrm{P}_{0}$ range from 0.7 to 0.98 , which may be due to the presence of a large pore volume and a small surface are. Aluminate ALD overcoating makes the $\mathrm{Cu}$-chromite catalyst lose surface area from $34.5 \mathrm{~m}^{2} / \mathrm{g}\left(\mathrm{Cu}\right.$-chromite) to $9.3 \mathrm{~m}^{2} / \mathrm{g}$ (ALD Cu-chromite-45c-700) and also 
lose the amount of $\mathrm{N}_{2}$ adsorbed during BET characterization. Then the corresponding pore size distributions from desorption branch (equilibrium transition) were shown in figure S1(b). The pore diameters for uncoaved and ALD overcoated catalysts ranges from $2 \mathrm{~nm}$ to about $100 \mathrm{~nm}$. The most concentration of pore distributions located at $11 \mathrm{~nm}$. The distribution of pore diameters becomes smaller when alumina ALD applied, small pores with the diameter less than $3 \mathrm{~nm}$ dismissed after 30cycles used. 10 cycles sample is a little different from the other samples on the pore diameter distributions. That may be because the thickness of ALD layers for ALD Cuchromite-10c-700 is smaller than the other ones, and the pore distribution within the ALD layers was influenced by the thickness of the ALD layers.
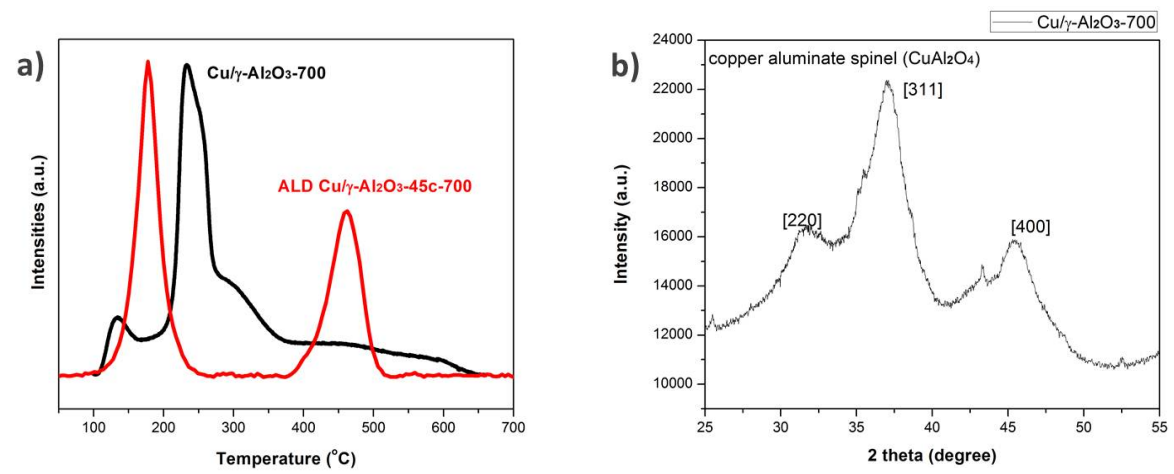

Figure S2(a) Temperature-programmed reduction $\left(\mathrm{H}_{2}-\mathrm{TPR}\right)$ of ALD Cu/ $\gamma-\mathrm{Al}_{2} \mathrm{O}_{3}-45 \mathrm{c}-700$ and $\mathrm{Cu} / \gamma-\mathrm{Al}_{2} \mathrm{O}_{3}-700$; (b) $\mathrm{XRD}$ spectrum of $\mathrm{Cu} / \gamma-\mathrm{Al}_{2} \mathrm{O}_{3}-700$. It is clear that the $\mathrm{Cu} / / \gamma-\mathrm{Al}_{2} \mathrm{O}_{3}-700$ contains big percentage of copper aluminate from $\mathrm{Cu} / / \gamma-\mathrm{Al}_{2} \mathrm{O}_{3}$ calcination at $700{ }^{\circ} \mathrm{C}$ for $5 \mathrm{~h}$.
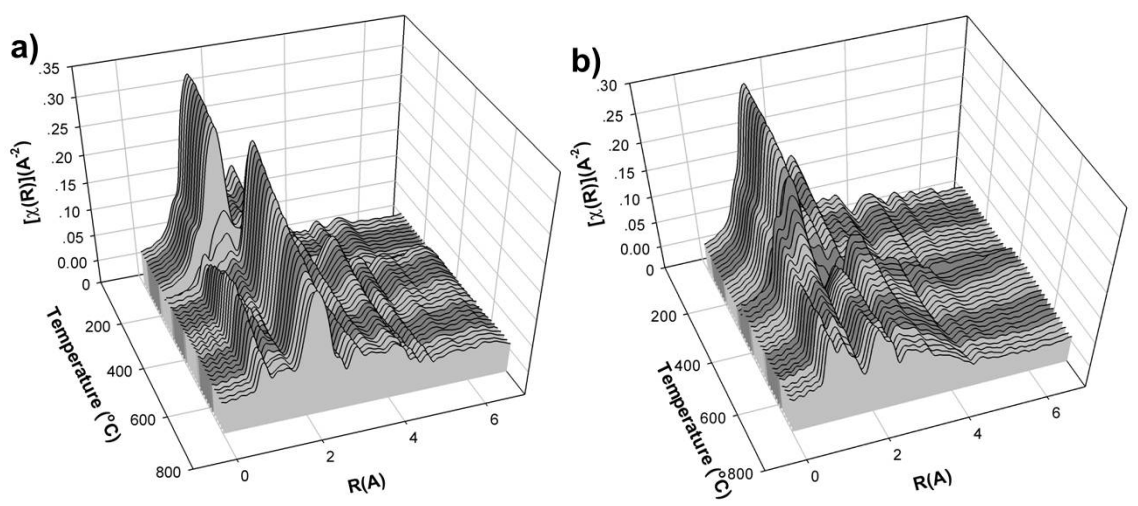
Figure S3. Cu FT-XAFS spectra of in situ $\mathrm{H}_{2}$-TPR on (a) Cu-chromite and (b) ALD Cu-chromite.
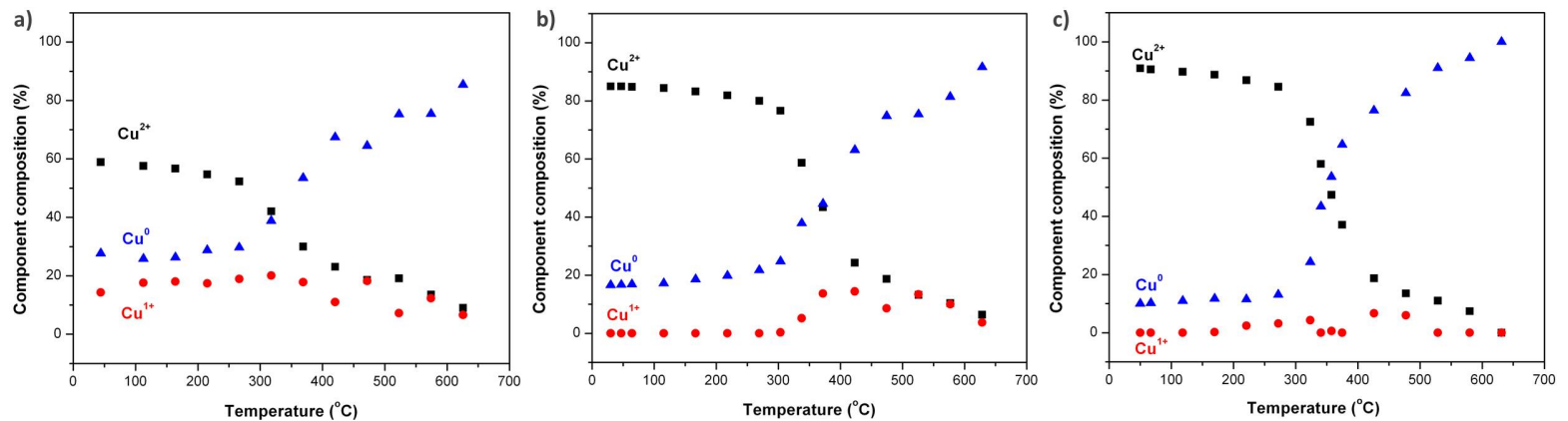

Figure S4. Percent of the different $\mathrm{Cu}$ species as a function of temperature during in situ XAFS/ $\mathrm{H}_{2}$-TPR from XANES data by linear combination fittings over different layers of ALD overcoatings, (a) ALD Cu-chromite-10c-700, (b) ALD Cu-chromite-20c-700 and (c) ALD Cuchromite-30c-700; $\mathrm{Cu}$ foil (Aldrich, 99.999\%), $\mathrm{Cu}_{2} \mathrm{O}$ (Aldrich, 99.99\%) and $\mathrm{CuO}$ (Aldrich, 99.999\%) were used as the standards to generate these results.

Table S1. Reaction performance of Cu-chromite, ALD Cu-chromite-10c-700, ALD Cu-chromite20c-700, ALD Cu-chromite-30c-700 and ALD Cu-chromite-45c-700.

\begin{tabular}{|c|c|c|c|c|}
\hline & Conversion (\%) & FA Selec. (\%) & 2-MF (\%) & $\begin{array}{l}\text { Reaction Rate } \\
\left(\mathrm{mMol} / \mathrm{g}_{\mathrm{Cu}-\text { surf }} * \mathrm{~S}\right)\end{array}$ \\
\hline Cu-chromite & 20.3 & 100 & 0 & 1.21 \\
\hline ALD Cu-chromite-10c-700 & 27.6 & 95.8 & 4.2 & 0.72 \\
\hline ALD Cu-chromite-20c-700 & 12.2 & 97.5 & 2.5 & 0.36 \\
\hline ALD Cu-chromite-30c-700 & 9.7 & 98.6 & 1.4 & 0.33 \\
\hline ALD Cu-chromite-45c-700 & 9.3 & 100 & 0 & 0.37 \\
\hline
\end{tabular}

* Note: FA represents furfuryl alcohol and 2-MF represents 2-methyl furan, Cu-surf means copper on the surface. The conversion and selectivities were collected when the catalysts were stablized. 